\title{
European Integrated Care Horizon 2020: increase societal participation; reduce care demands and costs in Finnish context
}

\author{
Katja Heikkinen $^{1}$, Mari Lahti ${ }^{1}$, Johanna Berg ${ }^{1}$, Arina Kiseleva ${ }^{1}$, Sini Eloranta ${ }^{1}$ \\ ${ }^{1}$ Turku University of Applied Sciences, Finland
}

\begin{abstract}
This project is ptart of larger European level integrated care project led by HU University of Applied Sciences. In Finland, the integration of social and health care services has taken center stage in both the policy and practice arenas. The needs of many client groups, e.g. mental health client or older people, are many and varied.

Poor mental health considerably impairs well-being of the population and has considerable economic consequences like absence from work, early retirement and productive losses. In this, professionals with different training backgrounds co-ordinate their expertise in providing care for their shared clients. It provides a safe nexus for the exchange of knowledge and opinions, as well as a framework for reaching a consensus about appropriate health care delivery for a particular client or client cohort. The client should have an immediate access to integrated care, with a focus on rehabilitation in patient's social roles.

The aim of this project is support societal participation, quality of live and reduce care demand and costs in social and health care client. There is a need to better understand different integrated care approaches for social and health care and guide future implementation of new integrated care models.
\end{abstract}

Keywords: Integrated Care; social and health care: mental health: Horizon 2020 


\section{Introduction}

Care for people with long-term and complex care needs requires a great deal of coordination and collaboration. Without improved collaboration between social and healthcare professionals many people will use unnecessarily fragmented health care systems. In Finland as well as in many other countries, integrated care is seen as a possible solution to the growing demand for improved patient care in social and health care.

There is a health and social services reform in Finland. With the reform it will be reshape the structures and services in health and social care. With the reform will be objectively trying to reduce inequalities in health and wellbeing, improve the quality of services and the access to services - focus is in integrated care (Ministry of Social Affairs and Health).

Integration in care is the combination of processes and methods that facilitate integrated care and results directly benefits communities and patients or service users. (WHO, 2016). Challenge with the integrated care is that it cannot be concluded that one model best supports integrated care (WHO, 2016).

With this paper we represent the current situation of integrated care in Finland with the examples of mental care and older people services.

\section{Integrated care}

Integrated care is an approach to tackle care fragmentations, particularly implemented to improve care outcomes and care experiences in all levels (Goodwin, 2015). The process of integrated care starts with a full patient assessment, followed by coordinated services between the three levels of care providers. The care is then delivered to the patient at home or as close as possible (Bruce \& Parry, 2015; Evers \& Paulus, 2015; Lewis, 2015; Spicer, 2015; Cringles, 2002).

The main characteristic of integrated care is complexity. A good understanding of the various dimension of integration is the first step towards integrated care (WHO, 2016).

\section{Forms of integrated care}

Several taxonomies and conceptual frameworks have been developed to give a better understanding of integrated care. Typically, the taxonomies include type, level, process, breadth, and intensity of integration. Lewis et al. (2010) recognize four types of integration: organizational, clinical, service, and functional. Organizational integration can be defined as several organizations working together through a coordinated provider. Integration of care into a single and coherent process within/or across professions by using shared guidelines is clinical integration. Service integration is the integration of services on an organizational 
level through teams of multi-disciplinary professionals. Functional integration refers to the integration of back-office and non-clinical support, for example, through electronic patient records.

According to Nolte and McKee (2008), the breadth of integration depends on the scope of the integration process. It ranges from the integration of care for individuals, specific conditions or care groups, or an entire population. Similar to this, the three levels at which integration can be pursued are micro-, meso- and macro-. Micro-level integration aims to deliver coherent care for the individual, which can be achieved through personalized care plans. Meso-level integration seeks to provide integrated care to a particular care group with the same illness or conditions. The objective of macro-level integration is to deliver integrated care to an entire population through tailoring services according to the population needs (Curry \& Ham, 2010).

Integration of care can be categorized according to its intensity (Nolte \& McKee, 2008). While partial integration creates ties to support integration between two sectors to improve coordination, full integration combines health and social sectors into a new organizational model.

The distinction is also made between horizontal and vertical integration. Horizontal integration focuses on linking similar levels of care that support a specific client group. Vertical integration ties care providers across primary, community hospital, and tertiary care services to deliver best practice care and care transitions between providers (Leutz, 1999).

\section{Models of integrated care}

Integrated care models range from disease-specific and individual models to populationbased models (Bodenheimer, 2008). Group- and disease-specific models include the chronic care model, integrated care models for elderly and frail, and disease management programs (WHO, 2002; Ham et al., 2008; WHO, 2016). Individual integrated care models cover personal care planning, case management, and patient-centered medical home (American Case Management Association, 2002; Curry \& Ham, 2010). Population-based models are currently implemented by Kaiser Permanente and Basque country (Pines et al., 2015; Polanco et al., 2015).

While the distinctive features and core components of integrated care are possible to identify, there is no single organizational approach that best supports integrated care (Goodwin et al., 2014). The development of any integrated care model is solidly contextually-bound. Integrated care models can only succeed when taking into consideration the needs and characteristics of the population it seeks to serve (WHO, 2016). 


\section{Integrated care in social and health care in Finland}

Integrated care is mean organizational models designed to create collaboration within and between the different care sectors at the funding, administrative and/or provider levels (Kodner \& Kyriacou 2000).

In Finland, the integration of social and health care services has taken centre stage in both the policy and practice arenas. The integration of social and health care services is considered a key method for improving the quality of care and services as well as organizing them efficiently and cost-effectively. This requires that the client's needs are assessed as a whole and information flows smoothly between the care providers. The needs of many client groups, for example mental health client and older people, are many and varied, and it is impossible for anyone professional to assume full responsibility: integrated care is needed. (Couffinhal et al. 2016.)

In Finland, municipalities are responsible for both social and health care services, however in many cases there remains limited coordination. Insufficient integration of social and health services is a well-known problem in many countries, especially for frail older people and people with multiple chronic conditions. With $10 \%$ of clients responsible for around $80 \%$ of costs in Finland there is clearly great scope for improvement regarding integration and coordination. (Couffinhal et al. 2016.)

\section{Integrated care in older people services}

In Finland as well as many other countries it is now important to move towards integrated care for many client groups. Integrated care is particularly important to older people, for number of reasons. First, it is these people who are most likely to have multiple social and health care needs, which are influenced by physical, psychological, social and environmental factors that require multiple service responses (e.g. Eloranta et al. 2008, Ryan et al. 2009). Second, older people are frequent users of health services and recent research has shown that frequent users of health services are also more likely to use social services (Markle-Reid et al. 2006, Lemetti et al. 2017). Third, health professionals often have to take account of social needs when deciding which services to refer older people to (Dempsey \& Bekker 2002, Lemetti et al. 2017). A further reason why the collaborative approach to care delivery is 
pertinent for older people is that the population is ageing rapidly and older persons themselves are demanding a better quality of care (Vaarama \& Pieper 2006, Lemetti et al. 2019).

In older people care, integrated care is important because it is estimated that there are over 500 million people aged 60 and over worldwide. Collaboration between people in different care organizations and different professional group aims to provide seamless, functional good quality services within effective service chains of care to enable older people to live at home independently. (WHO 2013.)

\section{Involved parties}

Involved parties Alma Mater Europe Maribor Slovenia, University of Applied Sciences Valencia Spain, Jagiellonian University Krakow Poland, University Graz Austria, Kristiania University Oslo Norway, Salford University Manchester UK, University of Applied Sciences Turku Finland, University of Applied Sciences Utrecht The Netherlands (secretary), Rotterdam Stroke Service The Netherlands, Vilans National Centre of Expertise for Longterm Care The Netherlands, NIVEL Netherlands Institute for Health Services Research, International Foundation of Integrated Care IFIC.

\section{Conclusion}

Efforts to move towards integrated care in social and health care have been met with increased interest and enthusiasm in recent years. This will increase the focus to improve care and population health while containing costs. However, there is a need to better understand different integrated care approaches for social and health care and guide future implementation of new integrated care models. For example, poor mental health considerably impairs the well-being of the population and has considerable economic consequences like absence from work, early retirement, and productivity losses.

It is now essential to move towards integrated care for many client groups e.g., mental disorders. In this, professionals with different training backgrounds co-ordinate their expertise in providing care for their shared clients. It provides a safe nexus for the exchange of knowledge and opinions, as well as a framework for reaching a consensus about 
appropriate health care delivery for a particular client or client cohort. The client should have immediate access to integrated care, with a focus on rehabilitation in a patient's social roles.

\section{References}

American Case Management Association. (2019). Definition of case management.

Bodenheimer, T. (2008). Coordinating care - a perilous journey through the health care system. The New England Journal of Medicine, 358(10), 1064-71.

Bruce, D., Parry, B. (2015). Integrated care: a Scottish perspective. London Journal of Primary Care (Abingdon), 7(3), 44-48.

Couffinhal, A., Cylus, J., Elovainio, R., Figueras, J., Jeurissen, P., McKee, M., Smith, P., Thomson, S. \& Winblad, U. (2016). International expert panel pre-review of health and social care reform in Finland. Reports and Memorandums of the Ministry of Social Affairs and Health 2016:66.

Cringles, M. C. (2002). Developing an integrated care pathway to manage cancer pain across primary, secondary and tertiary care. International Journal of Palliative Nursing, 8. 247279.

Curry, N., Ham C. (2010). Clinical and service integration. The route to improved outcomes. The King's Fund.

Dempsey, O., Bekker, H. (2002). Heads you win, tails you lose: A critical incident study of GPs' decisions about emergency admission. Family Practice 19, 611-615.

Eloranta, S., Arve, S., Routasalo, P. (2008). Multiprofessional collaboration promoting remaining capacity of older home care clients: Perspectives of older clients. International Journal of Older People Nursing 3, 88-95.

Evers, S. M., Paulus, A. T. (2015). Health economics and integrated care: a growing and challenging relationship. International Journal of Integrated Care, 15, e024.

Goodwin, N. (2016). Understanding Integrated Care. International Journal of Integrated Care, 16(4), 6.

Goodwin, N., Dixon, A., Andreson, G., Wodchis, W. (2014). Providing integrated care for older people with complex needs. Lessons from seven international case studies.

Ham, C., Glasby, J., Parker, H., Smith, J. (2008). Altogether now? Policy options for integrating care. Health Services Management Centre.

Kodner, D. L., Kyriacou, C. K. (2000). Fully integrated care for frail elderly: two American models. International Journal of Integrated Care. DOI: http://doi.org/10.5334/ijic.11 
Lemetti, T., Voutilainen, P., Stolt, M., Eloranta, S., Suhonen, R. (2017). Nurse to nurse collaboration on continuity of older people nursing care chain: qualitative study. International Journal of Integrated Care, 17(1), 5.

Lemetti, T., Voutilainen, P., Stolt, M., Eloranta, S., Suhonen, R. (2019). Older patients' experiences of nurse-to-nurse collaboration between hospital and primary healthcare on older people care chain. Scandinavian Journal of Caring Science, Jan 10. doi: 10.1111/scs.12653. [Epub ahead of print]

Leutz, W. N. (1999). Five laws for integrating medical and social services: lessons from the United States and the United Kingdom. Milbank Quarterly 77(1), 77-110.

Lewis, R., Rosen, R., Goodwin, N., Dixon J. (2010). Where next for integrated care organizations in the English NHS? London: The King's Fund.

Lewis, M. (2015). Integrated care in Wales: a summary position. London Journal of Primary Care (Abingdon), 7(3), 49-54.

Markle-Reid, M., Weir, R., Browne, G., Roberts, J., Gafni, A., Henderson, S. (2006). Health promotion for frail older home care clients. Journal of Advanced Nursing 54, 381- 395.

Ministry of Social Affairs and Health. http://www.euro.who.int/_data/assets/pdf_file/0005/322475/Integrated-care-modelsoverview.pdf

Nolte, E., McKee, M. (2008). Caring for people with chronic conditions: a health system perspective. Copenhagen: WHO on behalf of the European Observatory on Health Systems and Policies.

Pines, J., Selevan, J., McStay, F., George, M., McClellan, M. (2015). Kaiser Permanente California: A Model for Integrated Care for the Ill and Injured. The Brookings Institution.

Polanco, N.T., Zabalegui, I.B., Irazusta, I.P., Solinís, R.N., Del Río Cámara, M. (2015). Building integrated care systems: a case study of Bidasoa Integrated Health Organisation. International Journal of Integrated Care, 15.

Ryan, A. A., McCann, S., McKenna, H. (2008). Impact of community care in enabling older people with complex needs to remain at home. International Journal of Older People Nursing 4, 22-32.

Spicer, J. (2015). Integrated care in the UK: variations on a theme? London Journal of Primary Care (Abingdon), 7(3), 41-43.

Vaarama, M., Pieper, R. (2006). Managing Integrated Care for Older Persons. European Perspectives and Good Practices. STAKES \& EHMA. Gummerus Printing, Vaajakoski, Finland. 
World Health Organization. (2002). Innovative Care for Chronic Conditions: Building Blocks for Action.

World Health Organization. (2013) Towards people-centered health systems: An innovative approach for better health outcomes. Available at: http://www.euro.who.int/_data/assets/pdf_file/0006/186756/Towards-people-centredhealth-systems-an- innovative-approach-for-better-health-outcomes.pdf

World Health Organization. (2016). Integrated care models: an overview. Working document October 2016 Health Services Delivery Programme Division of Health Systems and Public Health. 